\title{
Review of the Petroleum Resource Rent Tax (PRRT)
}

Australian Government

The Treasury

Submission by Dr Cameron K. Murray for Prosper Australia

14 February 2017

About Prosper: Prosper Australia is a non-government think tank and tax reform lobby group inspired by economic efficiency and social justice. We advocate the fair distribution of land and natural resource rents. We contribute evidence and perspective to the national economic debate.

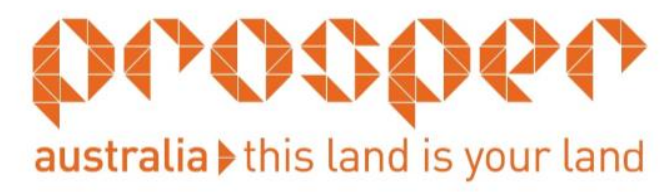




\section{Summary}

1. Successful reforms of oil and gas resource taxation that reclaim the public's rightful share of resource rents will be vigorously contested with extensive lobbying and campaigning. The oil and gas industry is also likely to challenge effective tax changes in the courts. If such industry actions do not occur, it is likely the reforms have been incomplete. After all, successful reforms will take billions of dollars a year of economic rent away from a handful of oil and gas companies and give it to the public. They will not be happy.

2. PRRT has some economic advantages in theory, including stabilisation effects in highly cyclical industries. However, these may be small in practice, as resource rent taxes are complex and difficult to enforce. A lesson from Norway is that taking an ownership stake in projects help enforce such taxes and provides insurance against their avoidance.

3. Previous changes to the PRRT have given ground unnecessarily to oil and gas companies. Changes to important details, like uplift rates on losses, transfer of PRRT credits between projects, and qualifying expenditure for the cost base, individually and cumulatively have had the effect of severely undermining the resource rent base of the PRRT. Closing these loopholes is necessary in order to effectively share resource rents with the public. In doing so, arguments about 'retrospective taxation' should be ignored, as protecting projects with their historical tax regimes simply hands over the economic rents any tax reforms are designed to collect for the public.

4. In the absence of a reformed PRRT that has an appropriate resource rent tax base, there are two alternative ways for the public to collect resource rents:

a. A $10 \%$ royalty on the market value of all oil and gas projects could replace all Commonwealth resource revenues from the suite of PRRT, crude excise and royalties. It would be simple to enforce and likely raise more revenues in the next decade as the industry unwinds from a large exploration phase. A $12 \%$ rate would be sufficient to replace Western Australia's share of North West shelf royalties as well.

b. A tax could be charged on pure economic rent using a system of self-declared unimproved resource values, with government holding a right to purchase at that value. An annual charge on this value at a rate slightly above the long-term bond rate would capture the majority of economic rents.

\section{PART 1: General comments on Terms of Reference}

\section{Return to the Nation while supporting resource development}

The review will have regard to the need to provide an appropriate return to the community on Australia's finite oil and gas resources while supporting the 
development of those resources, including industry exploration, investment and growth.

Australia is a resource rich nation that has only minimally attempted to recoup the value of the public's vast natural resources, despite being wealthy and politically stable. This has led to Australian governments at both the State and Federal levels missing out on a share of the windfall gains from a resources boom that began in 2004-05, now unwinding.

Total average annual revenues from the Commonwealth resource tax system on oil and gas were just $\$ 2.7$ billion per year during this historic boom period, while oil and gas producers reported $\$ 33.5$ billion in annual revenues on average and $\$ 8.2$ billion in annual profits.

This surprising low share of the value of the final oil and gas products, just $10 \%$ for all forms of resource taxation combinedi, is a product of overly generous exemptions and accounting practices that undermine each of the three main components of this Commonwealth resource tax system; gas royalties, crude oil excise tax and the Petroleum Resources Rent Tax (PRRT). The PRRT itself has seen its share of profits taxed fall from around half prior to 2000 , to less than $20 \%$ since 2010 (despite it applying on profits at a rate of $40 \%$ ), as the left panel of Figure 1 shows.
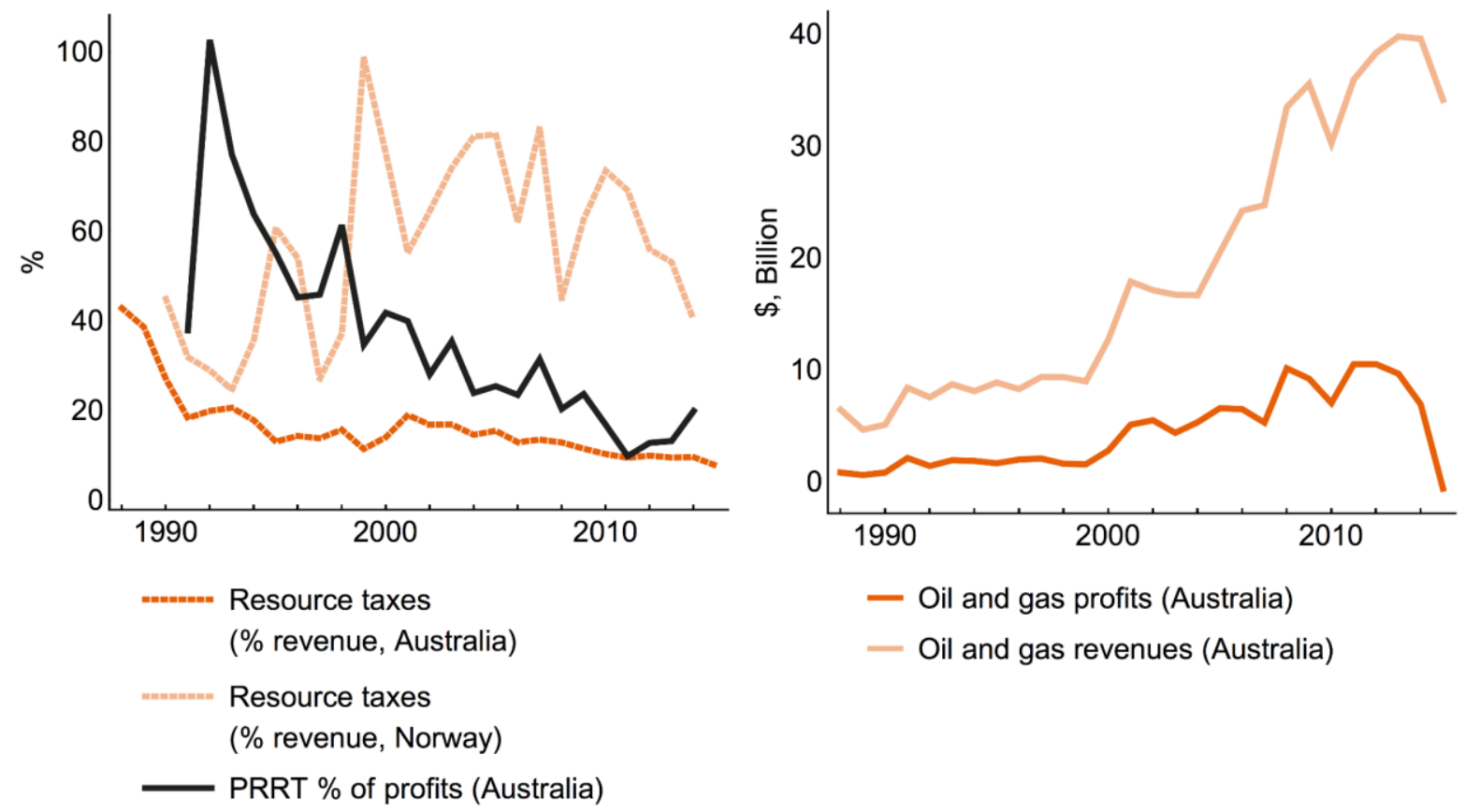

FIGURE 1: OIL AND GAS TAXATION, PROFITS, AND REVENUE (APPEA, 2016; STATISTICS NORWAY, 2016)

In comparison, Norway over this period exported NOK 555 billion in oil products per year on average, with the government reclaiming NOK 349 billion in taxes and payments for the Norwegian people; an astonishing $63 \%$ of total industry revenues.

A divergence between the rigorous resource taxing regime for oil and gas in Norway and the relatively light-handed taxation in Australia began in the mid-1990s.

As Figure 1 shows, Norway's system of reclaiming resource rents remained effective, growing the share of revenue captured by the public, while Australia's did not. This is despite the industry reporting enormous revenue and profit growth through the 2000s (right panel of Figure 1). 
In terms of providing an appropriate return on Australia's resource wealth, we provide some cautionary advice for the reform process.

a) The Review and the federal government should prioritise practicality of implementation and minimisation of tax avoidance, over and above considerations of economic efficiency. After all, any inefficiency in the sector will simply result in the resource being left in the ground to be utilised at some future date. The economic losses from using a blunt instrument like royalties, over a subtle and difficult to enforce instrument like the PRRT, may not be very large if poor PRRT design undermines the resource rent base it should be taxing.

b) The Review and the federal government should not be influenced by the flawed argument around 'retrospectivity' of changes to tax regimes. Such myths plagued past reforms of the PRRT system and the implementation of the Resource Super Profits Tax (RSPT), allowing generous exemptions and concessions to persist. These are nothing more than gifts of the economic rent the PRRT is meant to tax that are given to the lucky few resource companies who were historically dealt a favourable hand. Any changes that tighten up the accounting rules of the PRRT should apply broadly and replace previous arrangements. ${ }^{\text {ii }}$

\section{Design and operation of PRRT and economic considerations}

The review will examine the design and operation of the PRRT, crude oil excise and associated Commonwealth royalties that apply to the onshore and offshore oil and gas industry, having regard to economic conditions in the industry and trends over time.

The main comment we wish to make is that the accounting complexity of the current system provides the ability for companies liable for PRRT to fudge their numbers on multiple fronts. Compared to a pure royalty-only system, the current system is far more complex, relying on trust between oil and gas companies and ATO, as well as skilled, independent and well-funded tax auditors.

The major divergence between corporate taxes and PRRT paid by Australian oil and gas operations can be seen in Figure 2, with the left panel showing a sustained decline in PRRT paid as a percentage of profits, yet a flat share of corporate tax paid.

Clearly, the decline in PRRT revenues is not the result of these operations being less profitable.

Instead, it must be the result of accounting rules that differentiate between the tax base for corporate tax, and the tax base for PRRT; rules such as generous uplift on carry forward of losses, transfer of deductible costs between project, and so forth.

The right panel of Figure 2 shows that indeed, in the mid 2000's the expenditure of the industry began growing rapidly, providing ample opportunity to shift costs around their accounts to minimise PRRT obligations. Experience shows that generous interpretations of the accounting rules will be applied by oil and gas companies who have hundreds of millions of dollars of tax obligations on the line.iii 
In Part 2 of this submission it is further explained how these specific rules - more accurately, legal loopholes - shift resource rents back to oil and gas companies, and out of the PRRT tax base.
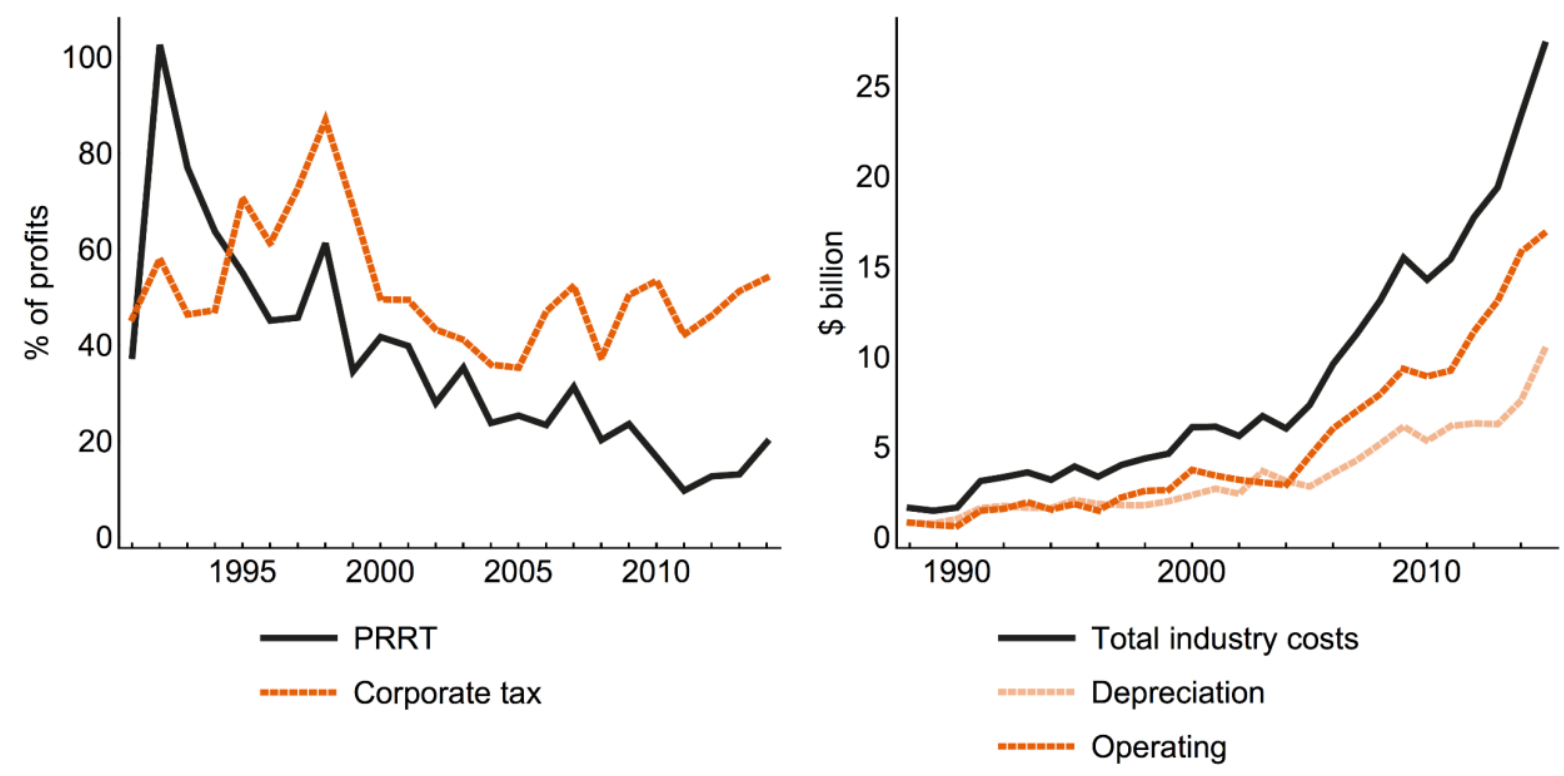

FIGURE 2: CORPORATE TAX AND PRRT FOR AUSTRALIAN OIL AND GAS COMPANIES (APPEA, 2016)

Complex systems such as these, which require judgments on multiple fronts when determining the proper accounting for the tax base are hard to enforce and easy to manipulate. A poorly designed PRRT may be worse economically than a simple royalty, as was made clear in the Review Issues Note with the following quotation.

There is not an unambiguous case for superiority of a resource rent tax versus a royalty in Australia. Detailed information about the relative costs of different mines, the importance of investments in exploration and in cost reductions over time, and the mobility of these investments across countries and other industries is required to quantify the trade-offs. It cannot be assumed that the ideal efficiency of a resource rent tax will be translated into practice. Simplicity, together with similar effects in collecting revenue from non-residents, favours staying with the status quo until more specific and believable data on key parameters becomes available.

- Professor John Freebairn (2015). "Royalties or Resource Rent Taxes?" Tax and Transfer Policy Institute, 10 December 2015.

One of the main arguments in favour of resource rent taxation is that it has a much larger dampening counter-cyclical effect than royalties alone. When resource prices are higher, a resource rent will rise more than in proportion to the price rise, while a royalty will only rise in proportion.

However, Australia has not seen such an effect in practice. The left panel of Figure 3 shows that PRRT revenues have been relatively flat since 2000 , while the two royalty-type taxes responded significantly to the boom cycle. This points to the failures in the design of the PRRT which undermine the resource rent tax base it should apply to. 
Resource rent taxes are more difficult to regulate and enforce in practice. If the agencies that design, implement, and enforce the tax are unable to do so independently and thoroughly, simple-toimplement alternatives should be considered, which we now discuss.

\section{a. Royalty only option}

To recoup the same revenue as the PRRT and existing excise and royalties did over the period 200405 to 2014-15, with a plain vanilla royalty applying to all offshore oil and gas projects as a percentage of market price, it would have need only be applied at $10 \%$ rate. This is below royalty rates that are standard in many countries - Argentina for example has a $12 \%$ royalty rate. iv

In Figure 3 the trends in Federal government revenues from the three major sources of taxation of oil and gas are shown in the left panel. In the right panel is the total current federal revenues, with a counterfactual $10 \%$ royalty applied to industry revenues, both of which would have provided $\$ 2.8$ billion in revenue per year since 2005. In addition, this exercise in determining the counterfactual royalty shows that it would have responded to the boom more than the PRRT did.

What this shows is that a simple royalty across the board, which is easy to enforce, difficult to avoid, and at a low rate compared many other countries, would have performed equally as well - if not better - than the current system in aggregate in the last decade.
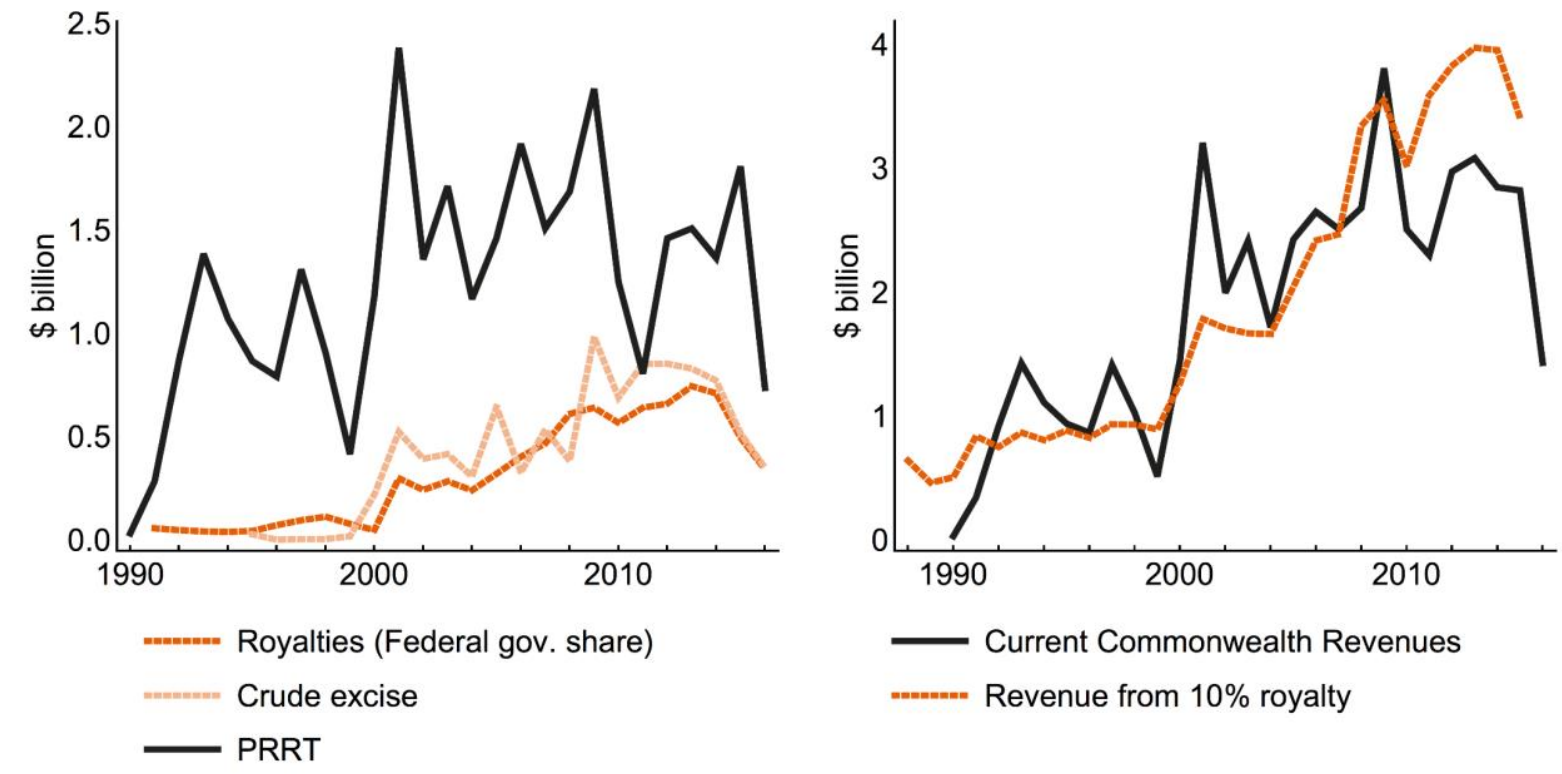

FIGURE 3: COMMONWEALTH RESOURCE REVENUE \& ROYALTY OPTION (AUSTRALIAN GOVERNMENT, 2016; APPEA, 2016)

Not only would a $10 \%$ royalty match the revenues to the public in the current system, but a simple royalty system is likely to deliver higher revenues than the current system in the coming decade. In 2015 the oil and gas industry as a whole reported a financial loss, indicating that both accounting profits (the tax base for corporate tax), and PRRT super-profits (the tax base for PRRT) will be massively eroded in the near future if market prices continue to remain subdued.

To take this example further, a $20 \%$ royalty rate would have provided revenues that were $250 \%$ of the current system over the past decade ( $\$ 6.8$ billion per year, compared to $\$ 2.7$ billion), with minimal effect on incentives and economic efficiency of the sectors. 


\section{b. Unimproved resource value taxation}

Under this option, each oil or gas producer would be need to self-declare the unimproved value of their resource assets each year. ${ }^{\vee}$ These valuations would be placed on a public cadastral map so the public and market competitors could observe them.

The oil and gas producers should then be required to pay a charge equal to the long-term bond rate, plus a small additional risk uplift (of 1-3\%) of the self-declared market value of the resource. To ensure the self-declared market value is realistic, the government would have the right to purchase the project (and its improvements) for the declared unimproved value plus compensation at the taxdepreciated value of structures.

This would provide incentives for competitors to approach the government to purchase assets if the declared unimproved value is low. Under such circumstance, the government could buy the oil or gas asset at the declared rate, and sell it to a competitor at the market rate, taking a further share of rents for the public.

\section{Previous policy decisions}

The review will also consider the impact of previous policy decisions on Commonwealth revenue.

A short commentary is made here, with more detail in the Part 2 of this submission.

One major recent policy change was in July 2012, when the PRRT was extended to onshore projects in the North West shelf area. This reform was accompanied by a transitioning measure that allowed companies affected to choose a 'starting base' of the value of their project based on their historical investment.

This starting base is an asset value which would then be allowed to be depreciated as deductible expenditure against PRRT for the next 25 years. The net effect is to shield the full economic rent of the project from the PRRT, since the market value of the project is the capitalisation of all future economic rents!

This move was either a massive mistake or was developed with a high degree of industry input and limited oversight from a frank and fearless public service. Either way, the lesson from this experience is that the argument of protecting previous investments, and against so-called 'retrospective taxation', should be ignored for the nonsense economics that it is.

\section{Comparison with international experience and recommendations}

Drawing on international experience, the review will make recommendations to the Government on future tax, excise and royalty arrangements having regard to revenue adequacy, efficiency, equity, complexity, regulatory costs and the impact on the industry generally.

International comparisons suggest that any effective method of capturing resource rents for the public will require heavy-handed government involvement in the sector. If this Review is unable to consider much greater involvement in the sector by government, such as taking ownership stakes in 
current oil and gas operations, or by investing in government-owned operations in new resources, than little genuine progress will be made.

What is rarely acknowledged is that the world-leader in resource taxation, Norway, gets around half its government resource revenues from direct ownership stakes in private companies, and its own State-owned oil operations (Statoil). When production licences are issued the government decides on a proportion of ownership stake to take, covering that share of investment and costs, and then later "receives a corresponding share of the income from production licences" (Norwegian Petroleum Directorate, 2017). This system is known as State's Direct Financial Interest (SDFI), and has generated $37 \%$ of the Norwegian governments income from oil rents over the past ten years, which was NOK 92 billion in 2015.

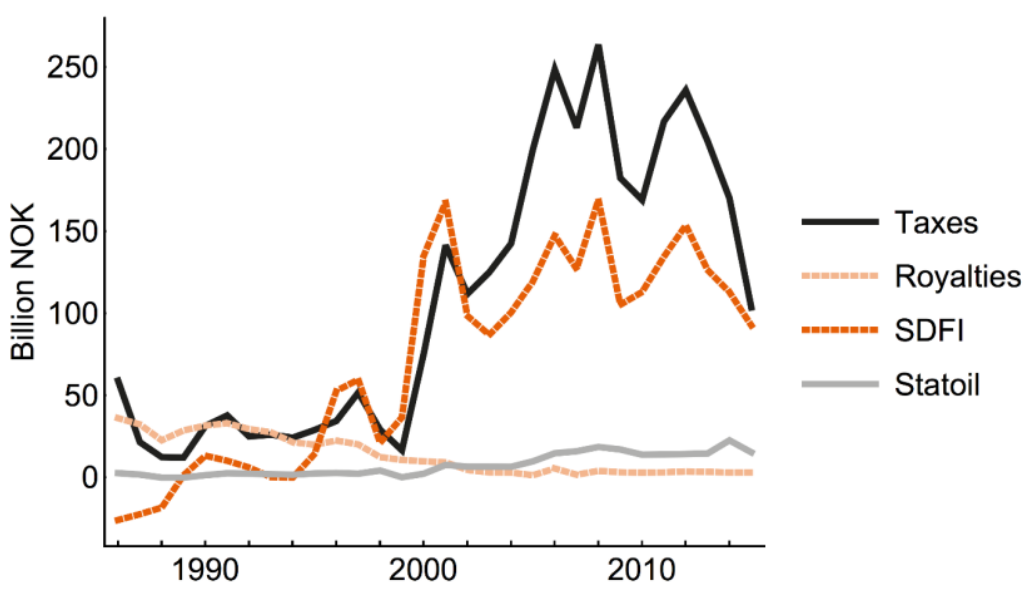

FIGURE 4: NORWEGIAN STATE REVENUE COMPOSITION FROM OIL AND GAS (STATISTICS NORWAY, 2016)

In Figure 4 is a breakdown of Norwegian government oil and gas revenues by type. It shows how returns from SDFI and (resource rent) taxes tracked the recent oil price boom much more than was the case in Australia (in Figure 3). The Norwegian resources rent tax takes $54 \%$ of the additional profits, after subtracting $24 \%$ company tax, and other uplifted deductions. There is no longer an interplay between royalties and resource taxes, as royalties have been phased out. Notably, the rate of resource rent tax of $54 \%$ is not radically higher than Australia's rate of $40 \%$ (noting the lower corporate tax rate in Norway), yet the tax is much more responsive to market conditions.

One of the reasons for their more effective system is the interplay between SDFI and the resource rent tax. Not only does buying into a project provide the government the advantage of being able to get an inside view of a project and the accounting used to determine tax obligations of all sorts, it also means that even when taxes are minimised through various loophole, the government still receives a share of additional profits from being an equity shareholder.

SDFI acts as both an enforcement mechanism for their resource tax, and an insurance policy against tax dodging. 


\section{Other matters}

A final important matter is to note the experience of a mining industry backlash against the proposed Resources Super Profits Tax (RSPT) in 2010. This proposed resource rent tax would have had the effect of transferring billions of dollars of economic rents to the public. The reaction of the industry - investing tens of millions of dollars in lobbying and campaigning - is the normal and logical outcome of effective tax reform that reclaims economic rents for the public.

There will be industry anger from PRRT reforms that also reclaim economic rents for the public.

Many myths about 'retrospective taxation' will arise in public debate. These need to be ignored if any reform effort is to be effective. Indeed, if the reforms are not challenged in court by the affected oil and gas companies, they can probably be judged as ineffective. Taxing economic rents is a battle over who gets billions of dollars, and the loser will go down fighting. 


\section{PART 2: Specific responses on Issues for Comment}

The overall performance of the PRRT, excise and associated Commonwealth royalty arrangements and whether they are operating as intended.

The economic rationale for PRRT over royalties levied as a percentage of market price of extracted resources is clear cut and correct. Prosper Australia has repeatedly argued for such taxes on the net value of resources, particularly land, for many years.

However, this does not mean that in practice they are the most efficient, given the trade-off between efficiency and enforceability. Indeed, a poorly designed resource rent tax, allowing generous cost deductions, high uplift of rolled-over losses, transfer of losses between projects, and other flexibilities that all favour the tax payer over the resource-owning public, is far inferior in terms of economic efficiency.

In Part 1, the pattern of PRRT tax revenues and profits in the Australian oil and gas industry was examined. One of the main messages was the PRRT revenues have been falling since 2004, despite rising profits and rising corporate taxes paid by the oil and gas industry. This means the design of the PRRT has elements that undermine its ability to capture resource rents. Some simple reforms could improve the ability to capture economic rents with the PRRT.

The reasons for the decline in petroleum taxation revenue including the impact of conditions in the industry and features of the tax regimes.

There are many reasons for the recent decline in PRRT revenues, which mostly relate to the following numbered items. In addition, it should be acknowledged that a component of the decline in resource tax revenues is probably due to standard profit shifting by multi-nationals, including transfer-pricing of brand inputs, exploration and rig investments. This obviously applies much more broadly than to resource taxation alone. But as noted in this submission numerous times, enforceability of a tax is in many ways more important than its efficiency.

The appropriateness of the following design features:

1. The treatment of carry forward losses and the level and structure of uplift rates under the PRRT.

Allowing losses to carry forward is standard accounting practice. However, the inflation of costs as they are brought forward into future time periods is not. This is a feature of the PRRT and other resource tax systems, which has little economic basis.

Generous uplift of cost deductions erodes the resource rental base. Norway, for example, allows uplift on carry forward losses at a declared interest rate only, currently $5.4 \%$, and only for expenditure carried over for less than 4 years (Australia allows 5 years). The $15 \%$ uplift above the Long Term Bond Rate (LTBR) is an extraordinary gift that undermines the resource rent tax base by allowing it to be minimised any time there is new investment by the owner of the PRRT project, whether it is related to the project or not. In practice it means that losses can be rolled over to reduce the PRRT tax base in later years with uplift of $10-20 \%$, depending the type of cost incurred. 
Changes to PRRT that applied from 2004-2008 that allowed a 150\% uplift for exploration in frontier areas were a pure gift from the public to oil and gas companies. Regardless of whether any exploration occurred, any money that could be put into a 'frontier exploration accounting bucket' would pay for itself in the following year through lower PRRT obligations (since every dollar is inflated to $\$ 2.50$, then deducted against a $40 \%$ PRRT tax rate the next year, reducing tax obligations dollar for dollar $[2.5 \times 0.4=1])$.

\section{Recommendation: Apply the LTBR as maximum uplift on all costs.}

\section{The transferability of deduction for the PRRT.}

In principle, all losses are transferable as credits under the PRRT for a company with multiple projects subject to the tax, if the project receiving the losses is already making a profit. This is the result of changes to the PRRT in 1991, a year after it began, that widened exploration cost deductibility from a project to a company basis.

This mechanism erodes the resource rental tax base without providing additional incentives for exploration. It is almost exactly like "negative gearing for oil and gas exploration". A major adverse effect is that companies who already have PRRT liable projects will have a higher return from exploration, crowding entry of any potential new competitors who cannot deduct explorations losses from other PRRT projects (which is especially valuable with an uplift), with no overall improvement in exploration incentives.

The erosion of the resource rental tax base arises as follows. The full market value of the resource rent occurs on a project-by-project basis. We know this because the sale of a single project from within a company would realise this capitalised value of this resource rent. If costs expended in unrelated exploration can be deducted against a profitable project, rather than quarantined against future profitable projects in the exploration area, it simply diminishes the resource rental base. The analogy with negative gearing is that transferring losses from investment property to wage incomes, rather than quarantining against future rental incomes, reduces the wages tax base.

\section{Recommendation: Quarantine deductibility of costs on a project basis.}

\section{The test for and scope of deductible expenses under the PRRT.}

PRRT deductible costs do not use the concept of 'necessarily incurred' which is used for income tax purposes. This loophole turns the PRRT system into an 'accounting bucket' into which companies with multiple projects can put any of their expenditure to gain deductions against the current and future PRRT obligations of the successful projects. The Issues Note has made this point clear, and we have no further analysis to add.

Recommendation: Require project costs deducted from PRRT base to be 'necessarily incurred'.

\section{The starting base arrangements in the extension of the PRRT in 2012.}

The look back method allows revaluation at market price as starting point, which defeats the purpose of extending the PRRT in the North West Shelf project. The market value already includes 
the capitalised value of resource rents, which now become deductible against future PRRT obligations. We agree with the commentary in the Issues Note. Any reform of PRRT and the Commonwealth resource tax system from this point forward should not quarantine historical rents given.

\section{Recommendation: Ensure reforms do not quarantine resource rents out of the tax base.}

\section{The order of deductions for the PRRT.}

This is a further complexity that should not be necessary. While the ordering can influence the cumulative uplift in costs, it is the uplift itself that is a problem. Furthermore, the order of deductions is clearly the result of previous policy changes that were overly generous and quarantined economic rents to oil and gas companies.

\section{Recommendation: As above in point 4.}

\section{The application of the PRRT to gas projects and floating LNG.}

As noted in the Issues Note, applying PRRT to integrated projects adds additional challenges. There are two main options for dealing with this. First, include LNG as a marketable petroleum commodity (MPC) under the PRRT, which would then apply to the integrated project. This would avoid any splitting of economic rents between the resource extraction and the downstream processing, which can (and does) happen in the calculation of the shadow price of the MPC. This is a first-best option and captures the full resource rent as the tax base in these cases.

A second option is to develop a method for establishing a 'shadow price' of gas before liquefaction, which is what has been done under the gas transfer pricing arrangements. Implemented well, this is a second-best option.

A third option also exists, which is the simplest of all, and that is to apply a royalty to the final liquefied product at a lower rate of market value. Where transfer pricing methods are imperfect and difficult to regulate, this may be a preferred option.

Recommendation: Consider a mechanism that does not require an administrative calculation of the shadow price of MPC by classifying final liquefied products as a MPC and treating the combined processing as a single investment.

\section{The gas transfer pricing arrangements under the PRRT.}

For integrated gas-to-liquids projects, PRRT currently applies only to the gas extraction phase, and hence a shadow price needs to be established at this intermediate stage (prior to processing as LNG), which determines revenues that apply to the PRRT calculation. Additionally, a division of costs is needed.

However, of the three current methods available to determine this non-market price and costs, all are subject to a high degree of accounting judgment. One option is to apply a netback method, that allows for a nominal profit rate on the project and a splitting of the residual rents in half between upstream and downstream parts of the project. As per the commentary in the Issues Notes from the 
Henry Tax Review, this method halves the rents upon which the PRRT applies. As such, this is a least preferred method (see comment 6 above for options to avoid the need for transfer pricing entirely).

Recommendation: As above in point .

8. The coverage and rate of crude oil excise.

Crude oil excise is an inclining block royalty-type tax system. We note that in the interest of simplification, similar systems such as the Barrow Island Resource Rent Royalty could be merged. We comment on the rate below.

Recommendation: Consider merging crude oil excise and Barrow Island Resource Rent Royalty.

9. Thresholds for exemption from crude oil excise.

The overall rates of crude oil excise have been reduced over time to make way for the PRRT, with new projects paying a zero rate on the first $500 \mathrm{ML}$ of annual production, and a maximum rate of $30 \%$ above $800 \mathrm{ML}$. There is also an exemption from the excise for the first $4,767 \mathrm{ML}$ of oil from a new field.

The economic logic for such high exemptions on crude excise is thin, and total annual production of crude oil and condensate is only around 20,000ML per year, meaning a large proportion of production must be paying no share of revenues, nor resource rents, to the public.

Shifting the inclining block schedule to have a no zero rate would increase the public's share of oil rents.

Recommendation: Remove exemptions so that all production incurs some crude excise.

10. The coverage of associated Commonwealth output based royalties.

Commonwealth output-based royalties apply to petroleum and gas production in the North West Shelf project area at a rate between 10 and $12.5 \%$ of wellhead value, and are shared with the Western Australian government. Our only comment is that by international standards this royalty rate is at the low end and could be ratcheted up to gain a larger share for the public.

Recommendation: Consider scope for increasing royalty rates as part of simplifying the overall Commonwealth resource tax system. 


\section{References}

APPEA. 2016. Financial Survey 2014-15. Australian Petroleum Production \& Exploration Association http://www.appea.com.au/appea-financial-survey-2014-15/

Australian Government. 2016. Review of the Petroleum Resource Rent Tax. Issues Note. 20 December 2016. http://www.treasury.gov.au/ConsultationsandReviews/Reviews/2016/Review-ofthe-Petroleum-Resource-Rent-Tax

Statistics Norway. 2016. The Petroleum Tax System. Norwegian Petroleum Directorate http://www.norskpetroleum.no/en/econom qy/governments-revenues/\#sdfi http://www.norskpetroleum.no/en/economy/petroleum-tax/ http://www.norskpetroleum.no/en/production-and-exports/exports-of-oil-and-gas/

Perpitch, N. 2016. North West Shelf royalty deductions not valid, audit finds. ABC News Online. 28 Nov 2016 http://www.abc.net.au/news/2016-11-28/north-west-shelf-royalty-deductions-notlegitimate-report-finds/8072670

\footnotetext{
i Including the share of royalties from the North West shelf oil project area that are shared with Western Australia.

ii Even if some operations reduce output in response to tax changes, the efficiency argument is still questionable. Producers already reduce output in response to market conditions. Why a reduction in output in response to new taxes that reclaim resource values for the public should be treated differently in terms of economic reasoning is questionable. If it is efficient to response to the market, it is efficient to respond to a more economically and socially appropriate tax system.

iii Attempts by producers in the North West shelf area to include unjustified deductions to reduce royalty obligations is just one recent example (Perpitch, 2016).

iv To meet the total Federal revenue, and Western Australian revenue from North West shelf royalties, to overall rate would need to be $12 \%$.

${ }^{v}$ This option has been put forward as the first-best way to collect resource rents by Terry Dwyer. We see it as one of many options, with the main consideration of choosing which way to collect resource rents being its practical effect.
} 